\title{
Study of an Annular Two-Phase Thermosyphon Used as an Isothermal Source in Thermometry
}

\author{
Florencio Sánchez-Silva* - Ignacio Carvajal-Mariscal - Ariel E. Moreno-Cordobés - \\ Pedro Quinto Diez - Miguel Toledo Velázquez \\ National Polytechnic Institute, School of Mechanical and Electrical Engineering, Mexico
}

The feasibility of using an annular two-phase thermosyphon (TPT) in thermometry was studied experimentally; the main results are presented in this paper. The TPT was conceived as an isothermal source for calibration purposes, using the comparison method. For this purpose, an annular TPT was designed, built and characterized, using water as a working fluid. In order to determine experimentally how isothermal the TPT annular surface can be, eight thermocouples were installed axially on its surface.

Tests were performed for two different cooling water flows $16.67 \mathrm{~cm}^{3} / \mathrm{s}$ and $4.17 \mathrm{~cm}^{3} / \mathrm{s}$. For each cooling water flow, four heat power levels were supplied in the evaporation zone: $(38,154,350,1,385) W$. The experimental results have shown that the thermal device works isothermal for power levels higher than $350 \mathrm{~W}$, where the so-called bar effect is not present and the temperature measurement error is reduced.

Key words: thermometry, two-phase thermosyphons, isothermal, annular, calibration

Highlights

- Using an annular two-phase thermosyphon as isothermal source in thermometry.

- Immersion depth of the temperature sensor is $21 \mathrm{~cm}$.

- Higher values of heat supplied promoted isothermicity.

- $\quad$ Device efficiency was higher than $94 \%$.

- $\quad$ The system accomplished all the requirements for calibration of temperature instruments using the comparative method.

\section{O INTRODUCTION}

The definition of a temperature scale, independent of the substance thermometric qualities used, was proposed by Kelvin in 1898 and was named the thermodynamic temperature scale, which coincides with a thermometer scale filled with a perfect gas. However, achieving this scale is practically impossible; therefore, another temperature scale was developed, the nearest possible to the thermodynamic one and fully characterized to remain convenient and maintain its precision.

Taking into account all these specifications, the international temperature scale (ITS) was created; it is updated every 20 years. This scale is based on a primary set of fixed points of temperature, for instance: the triple point of water, the melting point of gallium, the freezing point of zinc among many others. One of the calibration methods is based on the use of cells containing the fixed points cited in the ITS.

The other method of calibration is the comparison method, in which both the thermometer to be calibrated and the reference thermometer (calibrated one) are placed in an isothermal bath. The American Society for Testing and Materials (ASTM) established the calibration procedure to be followed when using this method [1]. For this purpose, a highly stable isothermal reservoir is required in order to avoid the socalled bar effect; this thermal phenomenon produces heat gains or losses due to the axial thermal gradient that appears when one end of the bar is in contact with the thermal source and transfers heat as a fin [2]. This situation leads to significant errors in temperature measurements, according to European Association of National Metrology Institutes EURAMET [3] and [4]. Reiss was a pioneer: he suggested using heat pipes to compensate the error induced by the bar effect in the calibration of thermometers [5].

Sostmann [6] and Bienert [7] proposed the use of heat pipes in thermometry; they pointed out that heat pipes are normally designed to transport the maximum heat flow with the minimum possible temperature difference. However, in thermometry applications, the heat transport capacity is less relevant than the device's isothermal behavior.

Tamba et al. evaluated a water heat pipe, controlling the operation pressure, when it was used as a comparative furnace in order to calibrate a standard platinum resistance thermometer (SPRT) in a range of $338.15 \mathrm{~K}$ to $430.15 \mathrm{~K}$, in a direct comparison against the reference SPRT, the combined uncertainty was estimated as $3.1 \mathrm{mK}$. These results show that 
his system had a good performance for calibration purposes [8].

Noorma et al. used a water heat pipe as a black body, i.e. as a reference spectral radiator in order to be used as heat source between $323.15 \mathrm{~K}$ and $523.15 \mathrm{~K}$; this was adopted by the National Institute of Standards and Technology NIST [9].

In contrast, isothermal furnaces have also been developed on heat pipe bases, but they require 30 minutes to achieve a stable operation temperature; Tasneem has proposed a cylindrical cavity in which the temperature is stabilized. The calibration is done using the cavity as a black body; the cylindrical cavity is filled with graphite in order to make the temperature uniform [10].

In this article, the experimental results of an annular TPT thermal characterization are presented; the goal is to determine its isothermal behavior and the time it takes to achieve this state of operation. The latter is the TPT's most significant characteristic for thermometry applications.

\section{THEORY OF THERMOSYPHONS}

\subsection{Working Principles of Thermosyphons}

Closed TPT, also known as wickless heat pipe, is a simple but effective two-phase heat transfer device. It performs better in a vertical position, with the evaporator or zone where the heat is supplied at the bottom; in this position, it takes advantage of the gravity acceleration for bringing down the condensed vapor as a liquid film [11].

The working fluid is stored at the TPT bottom as a liquid pool. The container is an evacuated closed pipe filled with a certain amount of a suitable working fluid. The TPT is divided into three main sections; the evaporator section, the adiabatic section, and the condenser section. If heat is added to the evaporator section, the working fluid inside the pipe vaporizes and carries heat from the heat source to the condenser section, where heat is removed by a cooling system. The condensed working fluid returns to the evaporator section, taking advantage of the gravity force, and closing the cycle. Therefore, the condenser section of the TPT must be located above the evaporator section.

\subsection{Fundamentals for Calculation}

In order to fully characterize the TPT, an experimental and analytical study must be undertaken. The condensation can be modeled as taking place inside a vertical pipe but with the interface liquid-vapor strain stress taken into consideration. The convection coefficient in the condenser is normally compared to the one given by the Nusselt theory or against the extended Nusselt theory [11].

In 1916, Nusselt was the first to consider the condensation phenomenon in a vertical plate without stress in the interface. Faghri et al. extended the Nusselt theory to a laminar and turbulent flow inside a thermosyphon, flow reduction due to the condensation rate was evaluated [12]. Spendel [17] also studied the condensation problem in the TPT; the momentum equation in the steam region was numerically solved for the laminar case and film condensing analysis in the condensing region was to coupled it.

In contrast, in the specialized literature there are two general approaches that are extensions of Nusselt's film condensation theory and are used to include the variable strain stress in the TPT condenser interface. The first method empirically stablishes the friction factor between the two phases in order to satisfy the mass balance to take into account the axial steam flow. The second numerically solves the steam flow in 2D and couples it with the Nusselt analysis for the film condensation.

When TPT is at steady state, the total pressure drop in a closed cycle is the addition of the both phases pressure drop in the different TPT regions. The total balance must be equal to zero [13].

$$
\begin{aligned}
& P_{g}+\left(P_{V C}-P_{V E}\right)+\left(P_{L C}-P_{V C}\right)+ \\
& +\left(P_{L E}-P_{L C}\right)+\left(P_{V E}-P_{L E}\right)=0 .
\end{aligned}
$$

In the above equation, $\left(P_{V C}-P_{V E}\right)=\Delta P_{V}$ is the pressure drop in the vapour phase flow, between the condenser and the evaporator.

$\left(P_{L E}-P_{L C}\right)=\Delta P_{L}$ is the pressure drop in the liquid phase flow between the evaporator and the condenser.

$\left(P_{V}-P_{L}\right)_{E}-\left(P_{V}-P_{L}\right)_{C}=0 \quad$ represents the pressure difference in the interfaces liquid-vapour in the evaporator region and condenser region respectivelly, so that we can write:

$$
P_{g}+\Delta P_{V}+\Delta P_{L}=0
$$

This means that the total pressure drop in the three TPT regions must be equal to zero. Thereofre, the necessary condition for the TPT to function is:

$$
P_{g} \geq \Delta P_{V}+\Delta P_{L}
$$

This means that gravity is the system driving force, which must always be equal or superior to the total pressure drop in the system. The pressure drop in 
the liquid phase flow of the TPT working fluid can be determined using Darcy's equation:

$$
\Delta P_{L}=-\frac{\mu_{L}}{\rho_{L}} \frac{\dot{m}_{L}}{K} \frac{l_{e f f}}{A_{L}} .
$$

Because TPT has not a wick on its inner wall, permeability $K$ is a parameter depending on the system characteristics and the working fluid. Moreover, in the TPT, there is a countercurrent annular liquid-vapor flow, so the wavy interface is an important factor for the permeability magnitude. In contrast, $l_{\text {eff }}$ is the TPT effective length and is given by:

$$
l_{\text {eff }}=\frac{l_{E}}{2}+l_{a}+\frac{l_{C}}{2} .
$$

In order to determine the pressure drop in the vapour phase, the following equation can be applied:

$$
\Delta P_{V}=-\frac{8 \mu_{V}}{\rho_{V}} \frac{\dot{m}_{V}}{\pi} \frac{l_{e f f}}{r_{V}^{4}}
$$

Gravity effects are given by:

$$
P_{g}= \pm \rho_{L} g l \sin \theta
$$

where $\theta$ is the TPT inclination angle with respect to the horizontal. In our case, the TPT position is vertical with the evaporator at the bottom so, $\theta=90^{\circ}$ and the TPT gets the maximum driving force:

$$
P_{g}= \pm \rho_{L} g l \text {. }
$$

In contrast, it is well known that the transported heat flow by a TPT depends on the quantity of liquid working fluid that changes phase in the evaporator:

$$
\dot{Q}=\dot{m} L
$$

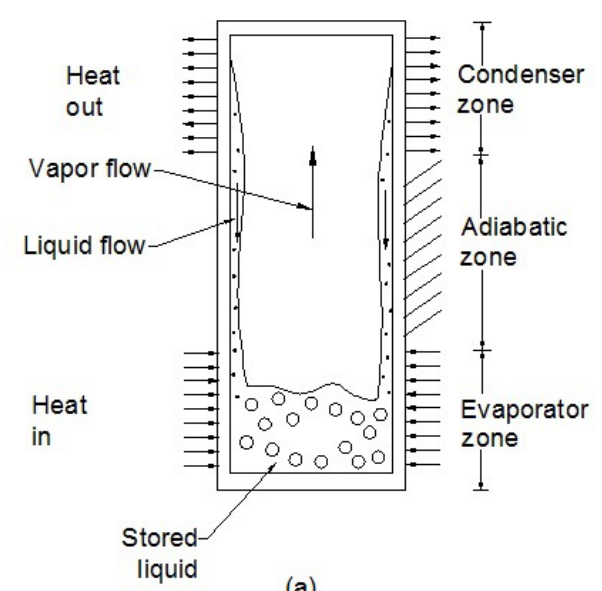

in which $L$ is the phase change enthalpy given by the expression:

$$
L=h_{V}\left(T_{S}\right)-h_{L}\left(T_{S}\right) .
$$

In order to maintain the TPT steady state operation, the liquid mass flow that evaporates in the evaporator must be equal to the vapour mass flow that condenses in the condenser, that is $\dot{m}_{L}=\dot{m}_{V}$. Next, the liquid mass flow is obtained by adding Eqs. (4), (6) and (8):

$$
\dot{m}=\frac{\rho_{L}^{2} g l K A_{L} \pi \rho_{V} r_{V}^{4}}{l_{\text {eff }}\left(\mu_{L} \pi \rho_{V} r_{V}^{4}+8 \mu_{V} \rho_{L} K A_{L}\right)},
$$

and the heat flow transported by a TPT is easily computed:

$$
\dot{Q}=\frac{\left(h_{V}-h_{L}\right) \rho_{L}^{2} g l K A_{L} \pi \rho_{V} r_{V}^{4}}{l_{\text {eff }}\left(\mu_{L} \pi \rho_{V} r_{V}^{4}+8 \mu_{V} \rho_{L} K A_{L}\right)} .
$$

\section{EXPERIMENTAL SECTION}

\subsection{TPT Design}

According to Faghri [11] and Sánchez et al. [14], the starting point in the TPT design for this kind of application is to know the temperature range in which the device is expected to work. With this information, the working fluid and the TPT body material are selected; both must be chemically compatible; moreover, in thermometry applications, the needed device dimensions are generally known, so it is desirable to use commercial pipes to build the annular TPT.

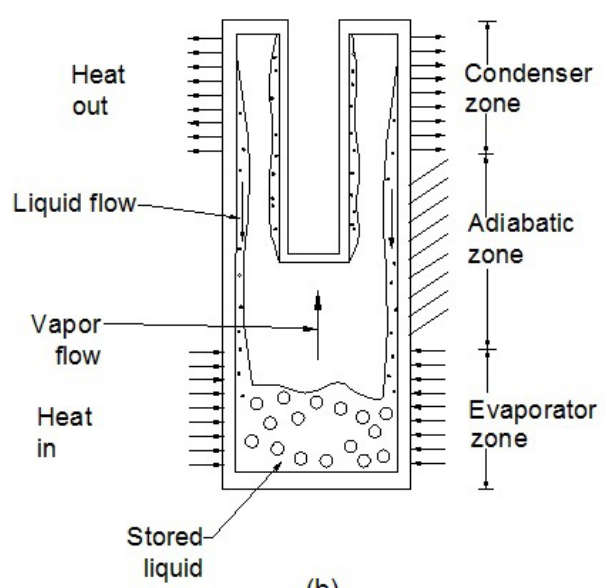

(b)

Fig. 1. a) A conventional TPT; b) A two-phase closed annular thermosyphon 
Based on this information, the heat flux supplied to the evaporator zone can be determined as well as the magnitude of cooling water flow to obtain the stable temperature operation in the system.

Fig. 1 shows both a conventional TPT and the annular TPT for thermometry applications. Both the conventional and the annular TPT are pipes sealed on both sides and, using a pump, a vacuum was created before the introduction of the working fluid; the difference is that the annular TPT has an annular cross section in the condenser zone, and the annulus is used as a volume where the thermocouples will be installed for calibration. The annular TPT technical specifications are summarized in Table 1.

Table 1. Annular TPT technical specifications

\begin{tabular}{lc}
\hline Total length & $500 \mathrm{~mm}$ \\
\hline Evaporator zone length & $200 \mathrm{~mm}$ \\
\hline Adiabatic zone length & $150 \mathrm{~mm}$ \\
\hline Condenser zone length & $150 \mathrm{~mm}$ \\
\hline External diameter of the TPT internal pipe & $28.6 \mathrm{~mm}$ \\
\hline Internal diameter of the TPT internal pipe & $26.2 \mathrm{~mm}$ \\
\hline External diameter of the TPT external pipe & $54 \mathrm{~mm}$ \\
\hline Internal diameter of the TPT external pipe & $50.8 \mathrm{~mm}$ \\
\hline External diameter of the condenser sleeve & $79.4 \mathrm{~mm}$ \\
\hline Internal diameter of the condenser sleeve & $74 \mathrm{~mm}$ \\
\hline Thermal insulation material & Mineral wool \\
\hline TPT body material & Copper \\
\hline Working fluid & Water \\
\hline Volume of the working fluid in the TPT & $130 \mathrm{~cm}{ }^{3}$ \\
\hline
\end{tabular}

For the $323.15 \mathrm{~K}$ to $523.15 \mathrm{~K}$ temperature range, the working fluid must be water. Copper type L was selected as the TPT body material; it withstands a pressure of 35 bar, even though the water saturation pressure at $373.15 \mathrm{~K}$, which is the expected operation temperature, is $101.325 \mathrm{~Pa}$. Both water and copper are chemically compatible so they can work together. The filling volume of working fluid was taken as $15 \%$ of the TPT free volume according to Faghri [11], Sanchez [15] and Carvajal et al. [16]. The annular TPT dimensions are shown in Table 1.

\subsection{Experimental System}

For the experimental system, a $373 \mathrm{~W}$ centrifugal pump was selected to guarantee the cooling water circulation in the condenser. The experimental rig has two reservoirs to store cooling water for condensation with a volume of $1 \mathrm{~m}^{3}$ each; both reservoirs are interconnected with a pipe located at the bottom of the tanks. For the heat supply system, a band electrical resistance was used; the resistance has an electrical power of $1,550 \mathrm{~W}$ and a resistance of $10.4 \Omega$. Fig. 2 shows a technical scheme of the experimental set up with all the elements. In Fig. 3 the annular TPT, the band type electrical resistance's installation, and the cooling system at the TPT top part are shown (all elements are without thermal insulation).

In order to change the power supply, a $120 \mathrm{VCA}$ potentiometer was used. The potentiometer provides

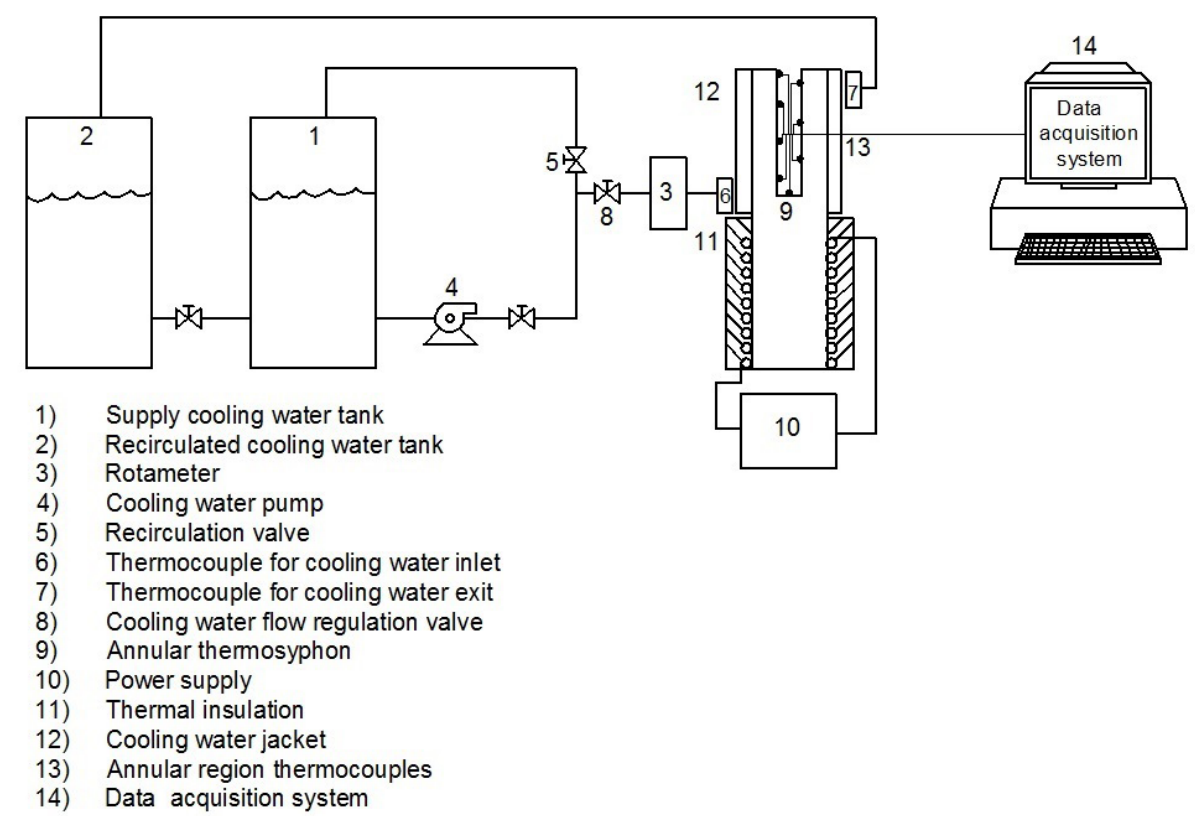

Fig. 2. Technical scheme of the experimental set up 
$0 \mathrm{~V}$ to $120 \mathrm{~V}$, and it had connected a voltmeter ( $\pm 0.05 \mathrm{~V}$ accuracy) in order to measure the voltage difference at the exit. A $0 \mathrm{~cm}^{3} / \mathrm{s}$ to $16.67 \mathrm{~cm}^{3} / \mathrm{s}$ range rotameter $\left( \pm 0.5 \mathrm{~cm}^{3} / \mathrm{s}\right.$ accuracy) was used to measure the cooling water flow. The thermocouples used were of the $\mathrm{K}$ type $\left( \pm 2.2{ }^{\circ} \mathrm{C}\right.$ accuracy in the temperature range studied). They were used to measure the temperature on the surface of the internal pipe wall that is the annular zone, and they were also used to monitor the temperature of the cooling water at the inlet and outlet of the condenser.

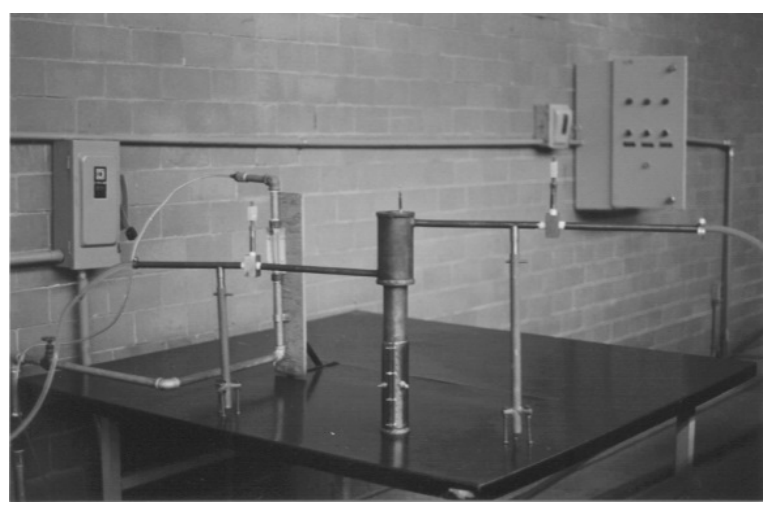

Fig. 3. The annular TPT experimental system showing the band electrical resistance on the evaporator

A digital thermometer $\left( \pm 0.5{ }^{\circ} \mathrm{C}\right.$ accuracy in the temperature range studied) with an Omega model HH-22 microprocessor was used for thermocouples type $\mathrm{J} / \mathrm{K}$. The thermocouples used in the experiments were located on the internal wall surface of the annular region, all the long its length and with a 3 $\mathrm{cm}$ separation between them, as shown in Fig. 4. The annular TPT was thermally insulated with mineral wool and was also covered with a sheet of aluminum.

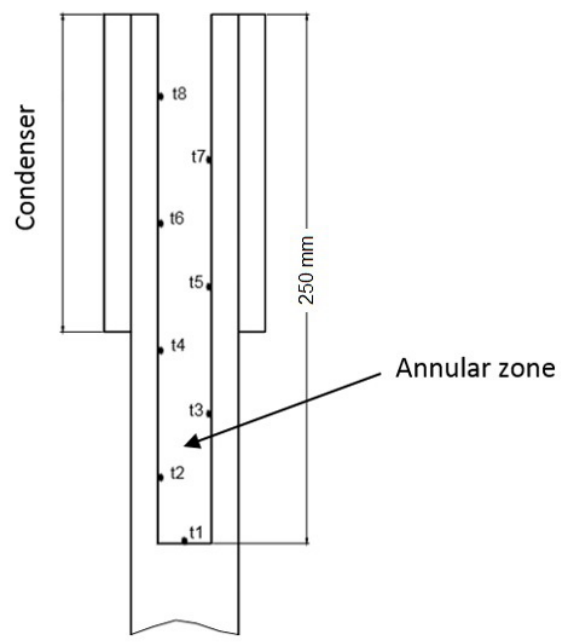

Fig. 4. Location of the thermocouples in the TPT annular region

\section{EXPERIMENTAL RESULTS AND DISCUSSIONS}

Experimental runs were undertaken in order to determine the time in which the annular TPT reaches a working steady state under different operating conditions. Therefore, thermocouples $\mathrm{t} 1, \mathrm{t} 5$ and $\mathrm{t} 8$ (see Fig. 4) were monitored during 30 minutes, i.e. the period in which the heating and cooling conditions were maintained at constant levels. Experiments were run for two different cooling water flows (16.67 $\mathrm{cm}^{3} / \mathrm{s}$ and $4.17 \mathrm{~cm}^{3} / \mathrm{s}$ ), and for each of them the power supplied was varied $(38,154,350,1,385) \mathrm{W}$ using the potentiometer to change the applied voltage according to Eq. (13)

$$
\Phi=\frac{V^{2}}{R}
$$

\subsection{Experimental Results}

The experimental results with cooling water flows equal to $16.67 \mathrm{~cm}^{3} / \mathrm{s}$ and $4.17 \mathrm{~cm}^{3} / \mathrm{s}$ are shown in Fig. $5 \mathrm{a}$ and $\mathrm{b}$. In these figures, it is possible to observe the temperature variation of the thermocouples $\mathrm{t} 1, \mathrm{t} 5$ and t8, located at the bottom, center and at the top of the annular region, respectively (Fig. 4), for three heat flow levels supplied to the evaporator: $154 \mathrm{~W}, 615 \mathrm{~W}$ and $1,385 \mathrm{~W}$.

For $16.67 \mathrm{~cm}^{3} / \mathrm{s}$, the cooling water flow temperature is slightly bigger for the thermocouple $\mathrm{t} 1$, but the difference against $\mathrm{t} 5$ and $\mathrm{t} 8$ is not more than $5 \mathrm{~K}$ for the same power level supplied (Fig. 5a). In contrast, for the cooling water flow of $4.17 \mathrm{~cm}^{3} / \mathrm{s}$ (Fig. 5b), the temperature difference between $\mathrm{t} 1, \mathrm{t} 5$ and $t 8$ is uneven; this means that the small cooling water flow is not enough to make the TPT temperature uniform. Practically, the TPT operation temperature for the small cooling water flow is always higher, and its behavior is uneven, especially in the case of $615 \mathrm{~W}$, in which $\mathrm{t} 1$, t5 and $\mathrm{t} 8$ show values of $(370,351,370)$ $\mathrm{K}$, respectively.

In contrast, in Fig. 6a and b, the percentage of the variation in temperatures $\mathrm{t} 1, \mathrm{t} 5$ and $\mathrm{t} 8$ in respect with lectures obtained with the same thermocouples, 30 minutes after the beginning of the experiment, is plotted against time. Therefore, the time needed for steady state operation was obtained using the relation:

$$
\% \Delta T_{30-i}=\frac{\left(T_{30}-T_{i}\right)}{T_{30}} 100 \% .
$$

Fig. 6a and $\mathrm{b}$ show the TPT temperature behavior for the cooling water flows of $16.67 \mathrm{~cm}^{3} / \mathrm{s}$, and 4.17 $\mathrm{cm}^{3} / \mathrm{s}$, respectively. For larger cooling water flows, 
there is a smooth tendency to the steady state, which is attained in $(18,28,18) \mathrm{min}$ for all the power supplied magnitudes, for $\mathrm{t} 1, \mathrm{t} 5$ and $\mathrm{t} 8$, respectively (Fig. 6a). In the case of the small cooling water flows, the behavior is more uneven; $\mathrm{t} 1, \mathrm{t} 5$ and $\mathrm{t} 8$ attain the steady state in $(20,24,18) \mathrm{min}$, respectively (Fig. 6b).

For the cooling flow of $4.17 \mathrm{~cm}^{3} / \mathrm{s}$, there is a difference of $5 \%$ in the thermocouple t1 for $615 \mathrm{~W}$ that vanishes after 28 min of operation; in contrast, the thermocouple 18 shows that the steady state takes place after $18 \mathrm{~min}$. As expected, the steady state is reached faster with larger cooling water flows.

To investigate in detail the isothermal behavior, the range of power supply values was broadened including $615 \mathrm{~W}$ and $960 \mathrm{~W}$. In Fig. 7, t1 to t8 indicate the thermocouples installed inside the annular region
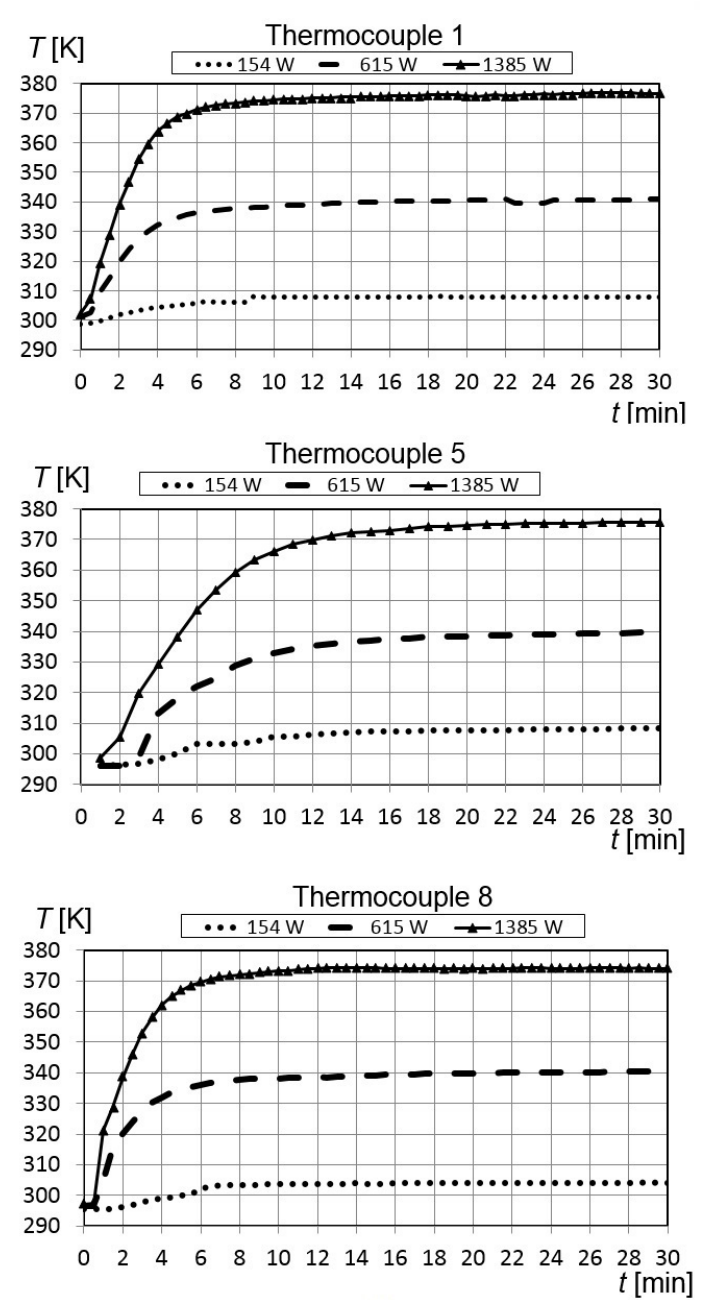

a) (see Fig. 4). The wall's isothermal behavior inside the annular region is evident, and this condition is easily attained for power supplied in magnitudes greater than $350 \mathrm{~W}$ in the evaporator. In this work, isothermicity is defined as such state when the temperature difference is not bigger than $3 \%$ along the TPT surface. It is important to note that the operation temperature values are always higher for the lower cooling water flow. For the power supplied in magnitudes of $38 \mathrm{~W}$ and $154 \mathrm{~W}$, the uniformity of the temperature profile is never achieved; therefore, there is an axial temperature gradient, and the annular TPT efficiency is reduced.

Practically, for the two cooling water flows used in the experiments $\left(16.67 \mathrm{~cm}^{3} / \mathrm{s}\right.$ and $\left.4.17 \mathrm{~cm}^{3} / \mathrm{s}\right)$ the steady state was obtained $18 \mathrm{~min}$ after the experiment
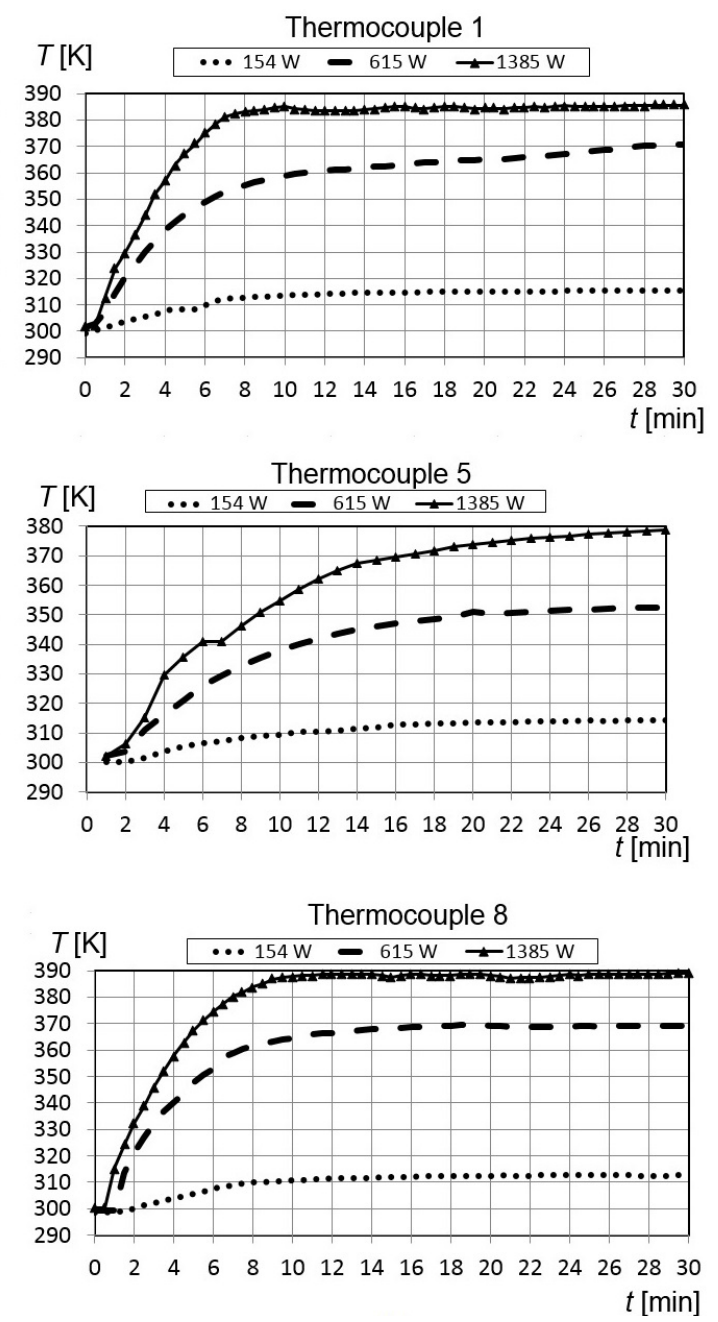

b)

Fig. 5. Temperature behavior measured by thermocouples $t 1, t 5$ and t8, for three heating conditions in the evaporator (154, 615, 1,385 W) versus time; a) for a cooling water flow of $16.67 \mathrm{~cm}^{3} / \mathrm{s}$ and b) for a cooling water flow of $4.17 \mathrm{~cm}^{3} / \mathrm{s}$ 
Thermocouple 1

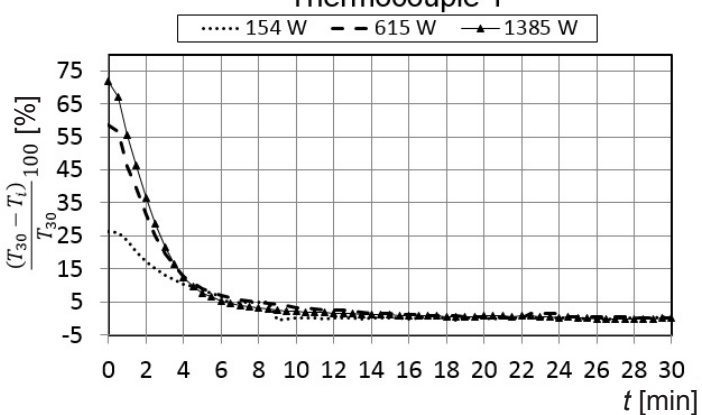

Thermocouple 5

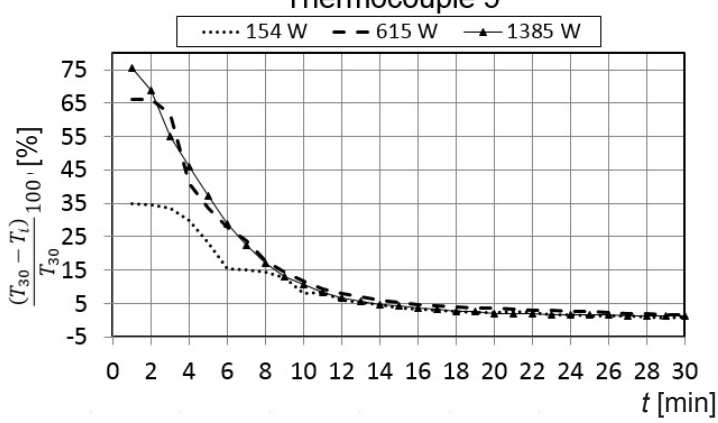

Thermocouple 8

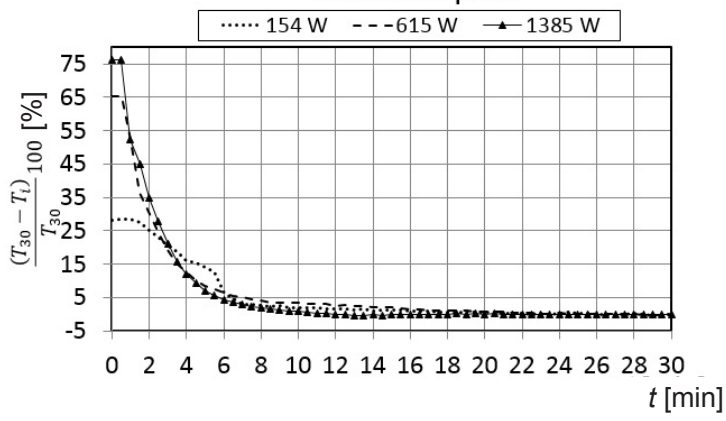

a)
Thermocouple 1

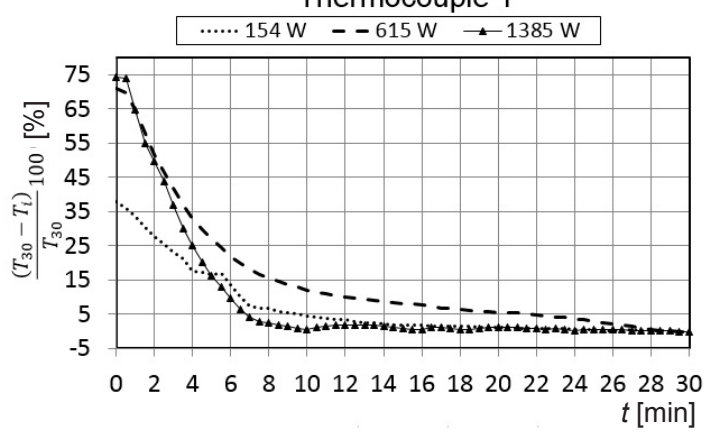

Thermocouple 5

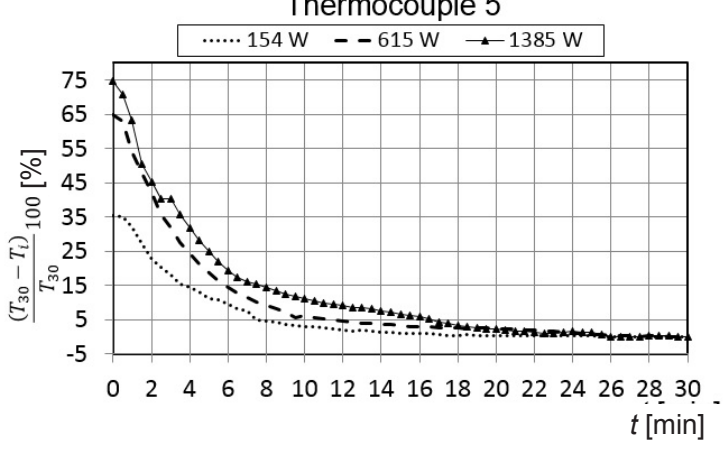

Thermocouple 8

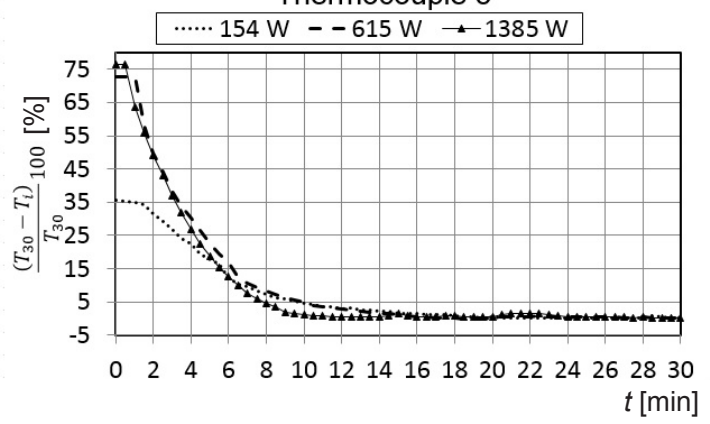

b)

Fig. 6. Percent variation of temperatures $t 1, t 5$ and t8 for three heat flow levels; a) for a cooling water flow of $16.67 \mathrm{~cm}^{3} / \mathrm{s}$ and b) for $4.17 \mathrm{~cm}^{3} / \mathrm{s}$

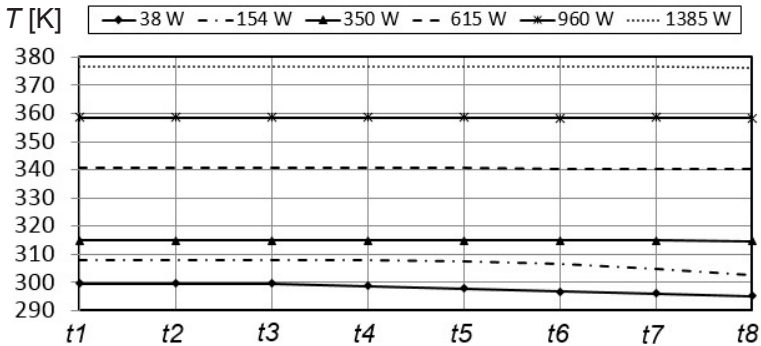

a)

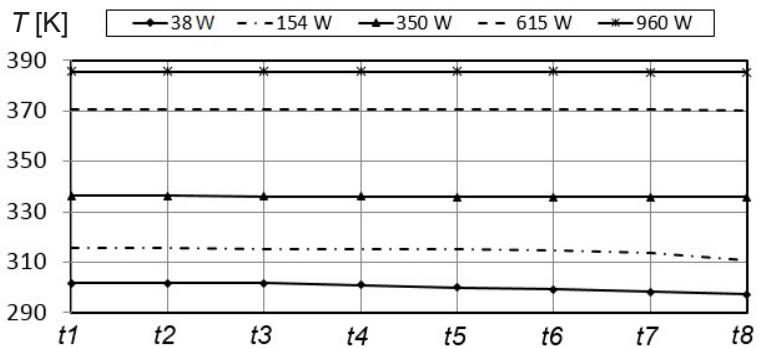

b)

Fig. 7. Temperature values measured for the different thermocouples t1 to t8 for 38, 154, 350, 615, 960 and $1385 \mathrm{~W}$ of heat flow levels supplied, with cooling water flow of a) $16.67 \mathrm{~cm}^{3} / \mathrm{s}$ and b) $4.17 \mathrm{~cm}^{3} / \mathrm{s}, 30$ minutes after the experiment start 
started (heat flow supply and cooling water flow maintained constant). For this period, there was a variation in temperature values of $2 \%$ in all analyzed cases.

\subsection{Results Discussion}

One of the objectives of this research was to evaluate the annular TPT as an isothermal source to calibrate temperature instruments, using the comparison method. In the experimental test, it was proved that TPT operation is isothermal along the $21 \mathrm{~cm}$ characterized annular zone length; consequently, the bar effect that produces a temperature measurement error, due to the axial temperature gradient, was avoided. Therefore, the device fulfills the requirements to be used as an isothermal reservoir for calibration purposes using the comparative method in the range from $313.15 \mathrm{~K}$ to $373.15 \mathrm{~K}$. Of course, when the required range of application is larger, the TPT working fluid should be changed, as well the cooling fluid and its flow.

In this research, the annular TPT immersion depth was $21 \mathrm{~cm}$, which can be easily extended by changing the device characteristics.

For the small heat flow magnitudes $(38 \mathrm{~W}$ and $154 \mathrm{~W}$ ), the heat flow supplied to evaporator is not sufficient to guarantee that the axial pressure gradient is near zero and consequently the axial isothermal behavior is not reached. Nevertheless, for heat flow supplied magnitudes higher than $350 \mathrm{~W}$ this effect disappears, as shown in Fig. 7. However, it is important to note that the annular TPT region operates at higher temperatures when the water cooling flow is reduced.

The other goal of this research is to propose the use of the TPT as a secondary reference for temperature instrument calibration. However,

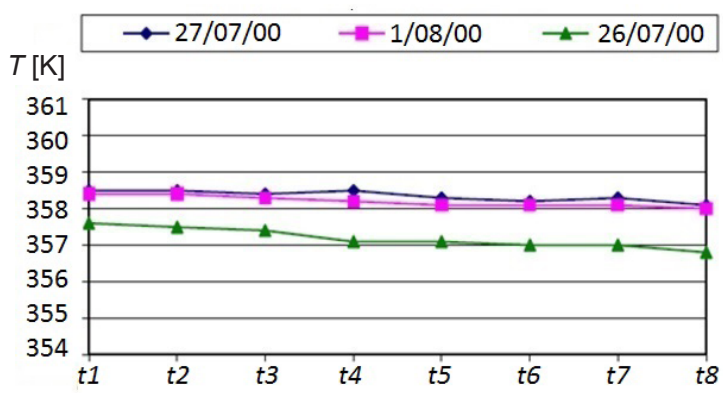

a)

Fig. 8. Repeatability of the axial temperature profile. Replay of the same experimental condition; a) $960 \mathrm{~W}$ and b) $1,385 \mathrm{~W}$ with $16.67 \mathrm{~cm} 3 / \mathrm{s}$ of cooling water flow, carried out in different days and on a different schedule this application implies a guarantee of the TPT stability and repeatability for different TPT working conditions; therefore, there should be the same values of temperature in different schedules using the same operation conditions.

Figs. $8 \mathrm{a}$ and $\mathrm{b}$ show the temperature profile on the annular region wall of the TPT, for three distinct experimental tests carried out in different days, but keeping the same operation condition $(960 \mathrm{~W}$ and $1,385 \mathrm{~W}$, with $16.67 \mathrm{~cm}^{3} / \mathrm{s}$ of cooling water flow), after 30 minutes of the experiment start. In the abovementioned graphs, it obvious that the temperature values are not strictly the same, and the differences were approximately of $4 \mathrm{~K}$ (i.e. $2.9 \%$ ): therefore, strictly speaking, the results are not reproducible.

This difference could be attributable to the cooling water temperature, which was not constant, because it depends on environmental conditions. In contrast, the other involved parameters (e.g. the electrical power supply and the cooling water flow) need to be controlled with a higher degree of precision.

In contrast, considering that the measured values obtained in different instants are not the same, it was not possible to obtain a calibration curve for the annular TPT in order to use it as a secondary reference for the calibration of temperature instruments.

In order to obtain a reliable TPT calibration curve and propose its use as a secondary reference for metrology purposes, it is necessary to keep constant, precise and stable the following parameters:

- Inlet cooling water temperature;

- Cooling water flow;

- Heat flow supplied magnitude in the evaporator.

Furthermore, even though the TPT is thermally insulated, it is also important to avoid any stream of air in the room where the experiments take place to avoid changing the surrounding conditions.

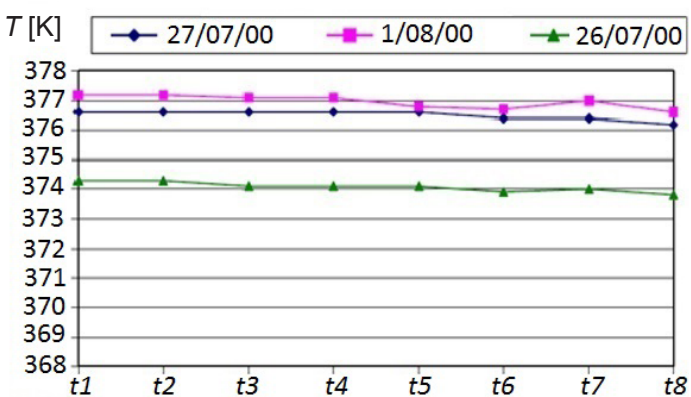

b) 
In order to evaluate the radial heat leakages, the thermal TPT efficiency was computed; this parameter was expected to be high because a TPT is similar to an ideal fin. The abovementioned is shown in Fig. 9, where the TPT efficiency is plotted at different operation power magnitudes, and was always higher than $94 \%$.

$$
\eta=\frac{\dot{Q}_{c}}{\Phi}
$$

Therefore, the device fulfills the requirements of an isothermal reservoir for calibration purposes using the comparison method. The range of the device's stable operation can be broadened by making some changes as previously mentioned.

In contrast, if the variations of the temperature are reduced by controlling the main parameters affecting the TPT stable operation and their precision, it would be possible to use the annular TPT as a secondary reference for calibration purposes.

The mean uncertainty of measured temperature in the range studied was $\pm 6 \%$.

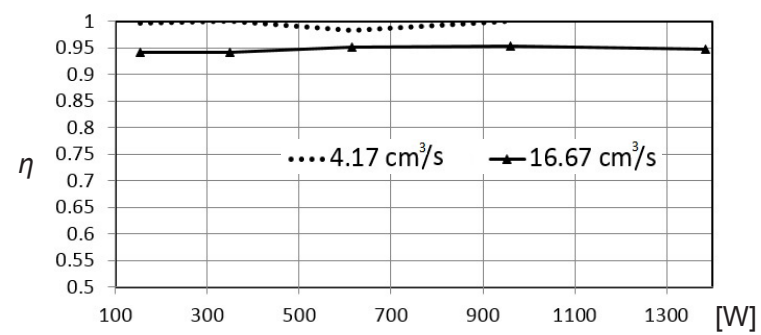

Fig. 9. TPT Efficiency for different operation conditions

Table 2. Uncertainty of voltage $V$ and power supplied $\Phi$

\begin{tabular}{ccc}
\hline Voltage [V] & $u_{V}[\mathrm{~V}]$ & $u_{\Phi}[\%]$ \\
\hline 40 & \pm 0.00124 & \pm 0.514 \\
\hline 60 & \pm 0.000814 & \pm 0.508 \\
\hline 80 & \pm 0.000598 & \pm 0.496 \\
\hline 100 & \pm 0.000482 & \pm 0.490 \\
\hline 120 & \pm 0.000410 & \pm 0.488 \\
\hline
\end{tabular}

Table 3. Uncertainty of heat flow transported, $\dot{Q}$ and efficiency $\eta$

\begin{tabular}{ccc}
\hline Voltage [V] & $u_{Q}[\%]$ & $u_{\eta_{1}}[\%]$ \\
\hline 40 & \pm 4.20 & \pm 4.23 \\
\hline 60 & \pm 2.88 & \pm 2.92 \\
\hline 80 & \pm 2.61 & \pm 2.66 \\
\hline 100 & \pm 2.55 & \pm 2.60 \\
\hline 120 & \pm 2.53 & \pm 2.58
\end{tabular}

The maximum uncertainties obtained for main variables calculated in the present study is uncertainty of electrical resistance, $R$ :
$u_{R}= \pm 0.00481 \Omega$.

\section{CONCLUSION}

An annular two-phase thermosyphon was designed, built and characterized, in order to evaluate its use in thermometry. Experiments were carried out for $16.67 \mathrm{~cm}^{3} / \mathrm{s}$ and $4.17 \mathrm{~cm}^{3} / \mathrm{s}$ cooling water flows with heat flow supplied magnitudes in the evaporator of $(38,154,350,615,960,1,385) \mathrm{W}$ for each cooling water flow.

Except in the cases of $38 \mathrm{~W}$ and $154 \mathrm{~W}$, the isothermal TPT characteristic was observed throughout the annular $21 \mathrm{~cm}$ length.

The system accomplishes all the requirements for an isothermal source for calibration of temperature instruments using the comparative method. The bar effect does not appear or is reduced. Therefore, temperature measurements do not need to be corrected to take in account this thermal effect.

According to isothermal behavior shown by TPT, it can be proposed as an isothermal source for the calibration of temperature instruments using the comparative method.

Another advantage is the immersion depth of the temperature sensor, which is $21 \mathrm{~cm}$, in this case. This value could be increased by changing the geometry of the annular TPT.

Regarding the repeatability of experiments, the cooling water temperature was not constant, because it depends on the surrounding conditions and other parameters involved, which were not fully controlled in the experiments (voltage, electric supply to the resistance terminals and cooling water flow). It was, thus, not possible to obtain the device calibration curve. Therefore, for experiments with the same operation conditions (heat flow supplied to evaporator and cooling water flow in the condenser), but in different schedules and days, there was not a good reproduction of the annular region temperature where the steady state was attained. Under these conditions, it is not possible to use the annular TPT as a secondary reference for calibration purposes.

\section{ACKNOWLEDGMENT}

The authors would like to thank the National Polytechnic Institute of Mexico and the National Science and Technology Agency of Mexico (CONACYT) for funding this research. 


\section{NOMENCLATURE}

$\begin{array}{lll}A & \text { area } & {\left[\mathrm{m}^{2}\right]} \\ K & \text { permeability } & {\left[\mathrm{m}^{2}\right]} \\ L & \text { change phase specific enthalpy } & {[\mathrm{J} / \mathrm{kg}]} \\ P & \text { pressure } & {[\mathrm{Pa}]} \\ \dot{Q} & \text { heat flow transported } & {[\mathrm{W}]} \\ R & \text { electrical resistance } & {[\Omega]} \\ T & \text { temperature } & {[\mathrm{K}]} \\ V & \text { electrical potential } & {[\mathrm{V}]} \\ g & \text { gravity acceleration } & {\left[\mathrm{m} / \mathrm{s}^{2}\right]} \\ h & \text { specific enthalpy } & {[\mathrm{J} / \mathrm{kg}]} \\ l & \text { length } & {[\mathrm{m}]} \\ \dot{m} & \text { mass flow rate } & {[\mathrm{kg} / \mathrm{s}]} \\ r & \text { radius } & {[\mathrm{m}]} \\ t & \text { time } & {[\mathrm{s}]} \\ u & \text { uncertainty } & {[-]}\end{array}$

Greek

$\begin{array}{lll}\Delta & \text { difference } & {[-]} \\ \Phi & \text { heat power supplied } & {[\mathrm{W}]} \\ \eta & \text { efficiency } & {[-]} \\ \mu & \text { dynamic viscosity } & {[\mathrm{Pa} \times \mathrm{s}]} \\ \rho & \text { density } & {\left[\mathrm{kg} / \mathrm{m}^{3}\right]} \\ q & \text { inclination angle } & {\left[{ }^{\circ}\right]}\end{array}$

Sub-index

$\begin{array}{ll}a & \text { adiabatic } \\ \text { eff } & \text { effective } \\ g & \text { gravity } \\ i & \text { instant } \\ S & \text { saturation } \\ \text { C } & \text { condenser } \\ E & \text { evaporator } \\ L & \text { liquid } \\ L C & \text { liquid in the condenser } \\ L E & \text { liquid in the evaporator } \\ Q & \text { heat flow transported } \\ R & \text { resistance } \\ S & \text { saturation } \\ V & \text { vapor, voltage } \\ V C & \text { vapor in the condenser } \\ V E & \text { vapor in the evaporator } \\ 30 & \text { after } 30 \text { minutes of exposition } \\ 30-i & \text { difference between } 30 \text { minutes and the time } i \\ \eta & \text { efficiency }\end{array}$

\section{REFERENCES}

[1] ASTM E 220-13, (2011). Standard method for calibration of thermocouples by comparison techniques. American Society for Testing and Materials, Philadelphia, DOI:10.1520/E0220.
[2] Mills, A.F. (1999). Heat Transfer, 2nd ed., Prentice Hall, Homewood, Boston.

[3] EURAMET (2011). Calibration of Thermocouples, EURAMET cg-8, Version 2.1., from: http://www.euramet.org/fileadmin/ docs/Publications/calguides/EURAMET_cg-8__v_2.1_ Calibration_of_Thermocouples.pdf, accessed on 2015-03-10.

[4] Bernier, M.A., Baliga, B.R. (1993). Effects of heat losses (or gains) from insulated portions of closed loop thermosyphons with vertical heat transfer sections. Journal of Heat Transfer, vol. 115, no. 2, p. 480-482, D0l:10.1115/1.2910705.

[5] Reiss, F.E. (1974). Heat pipe as a means of avoiding emergent stem correction for liquid in glass Thermometers. Review of Scientific Instruments, vol. 45, no. 9, p. 1157-1158, DOI:10.1063/1.1686831.

[6] Sostmann, H.E. (1991). The heat pipe and its use in thermometer calibration. ISOTECH Journal of Thermometry, vol. 2, no. 1, p. 31.

[7] Bienert, W.W. (1991). Isothermal heat pipes and pressure controlled furnaces. ISOTECH Journal of Thermometry, vol. 2, no. 1, p. 32-49.

[8] Tamba, J., Kishimoto, I., Arai, M., (2002). Evaluation of a Pressure-Controlled Water Heat Pipe for Accurate Comparison of Platinum Resistance Thermometers. Proceedings of the 41st Society of Instrument and Control Engineers, Osaka, vol. 4, p. 2435-2438, DOI:10.1109/SICE.2002.1195792.

[9] Noorma, M., Mekhontsev, S., Khromchenko, V., Litorja, M., Cagran, C., Zeng, J., Hanssen, L. (2006). Water heat pipe blackbody as a reference spectral radiance source between $50^{\circ} \mathrm{C}$ and $250^{\circ} \mathrm{C}$. Proceedings of the International Conference on Thermal Sensing and Imaging Diagnostic Applications, vol. 6205, D0l:10.1117/12.667257.

[10] Tasneem, K.A. (2009). Calibrating a thermocouple and investigating heat transfer. Technical Report: Heat transfer and thermocouples. Lahore University of Management Sciences, Lahore, from http://lums.edu.pk/docs/Calibration. pdf, accessed on 2015-03-10.

[11] Faghri, A., (1995). Heat Pipe Science and Technology. Taylor \& Francis Group, London.

[12] Faghri, A., Chen, M.M., Morgan, M. (1989). Heat transfer characteristics in two-phase closed conventional and concentric annular thermosyphons. Journal of Heat Transfer, vol. 111, no. 3, p. 611-618, D0l:10.1115/1.3250726.

[13] Chi, S.W. (1976). Heat Pipe Theory and Practice, McGraw-Hill, New York.

[14] Sánchez-Silva, F., Carvajal Mariscal, I., Tolentino Eslava, G., Abugaber Francis, J. (2001). Thermal and mechanical design of a two phase flow thermosyphon heat exchanger. Información Tecnológica, vol. 12, no. 3, p. 63-70. (in Spanish)

[15] Sánchez-Silva, F. (1980). Contribution to the study of twophase water thermosyphons, Ph.D. Thesis, Université de Poitiers, Poitiers. (in French)

[16] Carvajal-Mariscal, I., Sánchez-Silva, F., Polupan G., (2012). Development of High Efficiency Two-Phase Thermosyphons for Heat Recovery. Mitrovic, J. (ed.). Heat Exchangers - Basics Design Applications, p. 97-116, D0l:10.5772/32693.

[17] Spendel, T. (1984). Laminar film condensation heat transfer in closed two-phase thermosyphons. Proceedings of $5^{\text {th }}$ International Heat Pipe Conference, p. 208-213. 